\title{
Protein
}

\section{Farnesyltransferase/Geranylgeranyltransferase Type-1 Subunit Alpha}

National Cancer Institute

\section{Source}

National Cancer Institute. Protein Farnesyltransferase/Geranylgeranyltransferase Type-1

Subunit Alpha. NCI Thesaurus. Code C38601.

Protein farnesyltransferase/geranylgeranyltransferase type-1 subunit alpha (379 aa, 44 $\mathrm{kDa}$ ) is encoded by the human FNTA gene. This protein is involved in protein prenylation. 